Research Article

\title{
Cost-Effective Tween 80-Capped Copper Nanoparticles for Ultrasensitive Colorimetric Detection of Thiram Pesticide in Environmental Water Samples
}

\author{
Nguyen Tuan Anh $\mathbb{D}$, ${ }^{1}$ Ngo Xuan Dinh $\mathbb{D}^{1},{ }^{1}$ Hoang Van Tuan $\mathbb{D}^{1}$, Tran Hung Thuan $\mathbb{D}^{2}$ \\ Le Minh Tung, ${ }^{3}$ Van Phan Le, ${ }^{4}$ Doan Quang Tri $i,{ }^{5}$ and Anh-Tuan Le $\mathbb{C}^{1,6}$ \\ ${ }^{1}$ Phenikaa University Nano Institute (PHENA), Phenikaa University, Hanoi 12116, Vietnam \\ ${ }^{2}$ Center for Materials Technology, National Center for Technological Progress (Nacentech), Ministry of Science and \\ Technology (MOST), Hanoi 10000, Vietnam \\ ${ }^{3}$ Department of Physics, Tien Giang University, My Tho City, Tien Giang Province, Vietnam \\ ${ }^{4}$ College of Veterinary Medicine, Vietnam National University of Agriculture (VNUA), Trau Quy-Gia Lam, Hanoi, Vietnam \\ ${ }^{5}$ Advanced Institute for Science and Technology (AIST), Hanoi University of Science and Technology (HUST), 01 Dai Co Viet Street, \\ Hai Ba Trung, Hanoi 10000, Vietnam \\ ${ }^{6}$ Faculty of Materials Science and Engineering (MSE), Phenikaa University, Hanoi 12116, Vietnam
}

Correspondence should be addressed to Ngo Xuan Dinh; dinh.ngoxuan@phenikaa-uni.edu.vn and Anh-Tuan Le; tuan.leanh@phenikaa-uni.edu.vn

Received 19 February 2021; Revised 6 April 2021; Accepted 15 September 2021; Published 21 October 2021

Academic Editor: Dong Kee Yi

Copyright (C) 2021 Nguyen Tuan Anh et al. This is an open access article distributed under the Creative Commons Attribution License, which permits unrestricted use, distribution, and reproduction in any medium, provided the original work is properly cited.

\begin{abstract}
Thiram plays a critical role in protecting fruits and vegetables from damage by various crop diseases, but its residues significantly affect the environment, such as soil and water pollution, and becoming a serious threat to human health. Herein, Tween 80 capped copper nanoparticles (Tween 80-CuNPs) were developed as a convenient and low-cost colorimetric probe for selective detection of thiram pesticide. In the presence of thiram, the color of Tween 80-capped CuNPs changed from dark brown to olive green and colorless at high thiram concentrations. The Tween 80-capped CuNPs-based colorimetric probe exhibited good selectivity and high sensitivity (LOD about $0.17 \mu \mathrm{M}$ ) with a high linearity level in the calibration range of $0.5-25 \mu \mathrm{M}$ of thiram concentrations. The thiram limit of detection (LOD) of proposed sensor is lower than the maximum residue limit (MRL) regulated by the governments of EU and Vietnam. Moreover, the proposed sensor was successfully applied to determine thiram in tap water with percentage recovery of $98-107 \%$ and high repeatability $(\mathrm{RSD}=1.9 \%)$. The obtained results indicated that Tween 80-capped CuNPs would become a cost-effective sensing platform for ultrahigh-sensitive thiram determination in the environmental water samples.
\end{abstract}

\section{Introduction}

Presently, chemical pesticides are widely used in agriculture, especially in some developing countries [1]. In addition to their inherent effects, the chemical pesticide residues can affect the environment, such as soil and water pollution, directly affecting human health [2]. With increasing interests in the environment and human health, the detection of pollutants has drawn tremendous attention from academic researchers, industry, and governments. Dithiocarbamates (DTC) have numerous applications in chemical [3], agriculture [4], and the pharmaceutical industry [5], etc. Thiram (tetramethylthiuram disulfide) is a kind of typical DTC pesticide and fungicide which has been widely used to prevent various crop diseases [6]. However, its overuse has caused serious environmental hazards such as soil pollution and even seep into groundwater or mixed with air dust, therefore, becoming a serious threat to human health $[7,8]$. The European Union has limited the maximum 
allowable concentration for thiram in fruits, fresh or frozen, tree nuts about $0.1-10 \mathrm{mg} \cdot \mathrm{kg}^{-1}$ [9]. Currently, various analytical techniques for the detection of thiram residue, for instance, spectrophotometry combined with solid-phase extraction $[10,11]$, chromatographic methods (LC-MS) [12], LC coupled with tandem mass spectrometry (LC-MS/MS) [13], gas chromatography (GC) [14], enzyme-linked immunosorbent assay (ELISA) [15], and high-performance liquid chromatography (HPLC) with ultraviolet detection [16]. Despite the advantages, most of these techniques require time-consuming sampling and skilled personnel to operate complex and costly instrumentation, have lengthy processing, and are unable to widely apply these techniques, especially in the on-site analysis.

Among various current analytical methods, the colorimetric method has been demonstrated as a flexible analytical technique because of its susceptibility, rapid response time, cost-effectiveness, and great potential in point-of-care testing (POCT) to determine various pollutants in aqueous systems. LSPR is a unique property of noble nanoparticles due to the coherent oscillation of free electrons in the metal surface's conduction band. The intensity and position of the LSPR absorption band are mainly dependent on the size, shape, dielectric environment of single metal nanoparticles, and distance of NPs from one another [17]. The metal NP-based colorimetric sensors' principle is that a decrease in the interparticle distance leads to the changes of LSPR peak and intensity, causing an easily observable change in color solution [17].

Some noble metallic nanoparticles such as gold ( $\mathrm{Au})$ and silver (Ag) nanoparticles have received extensive and used as colorimetric sensors for the sensitive detection of various chemical/biological pollutant species such as metal ions, pesticides, drugs, glucose, and bacteria [18-20]. Several colorimetric sensors based on noble metal nanoparticles such as AuNPs and AgNPs have been developed to determine thiram pesticide. For example, Rohit and Kailasa [21] established a colorimetric method for on-site analysis of thiram and paraquat using cyclen dithiocarbamate-functionalised silver nanoparticles (CN-DTC-Ag NPs) with the limits of detection (LOD) were found to be $2.81 \times 10^{-6} \mathrm{M}$ and $7.21 \times 10^{-6} \mathrm{M}$ for thiram and paraquat, respectively. Rastegarzadeh and Abdali [22] developed an effective colorimetric sensor to detect thiram using gold nanoparticles modified with cetyltrimethylammonium bromide; these noble metals have a disadvantage of high costs of the AuNPs and AgNPs leading to expensive costs of colorimetric sensing systems. Copper nanoparticles (CuNPs) with surface plasmon resonance (SPR) properties similar to the AgNPs and AuNPs have been developed to reduce the costs of colorimetric-based sensing systems. Nevertheless, to the best of our knowledge, employment of Tween 80-capped CuNPs has not yet been investigated as a colorimetric sensor for detection of thiram residues. In this work, Tween 80 -CuNPs have been obtained through a simple method by using Tween 80 as a stabilizer and sodium borohydride as a reducing agent. Tween $80-\mathrm{CuNP}$-based colorimetric sensor has been developed and applied for ultrasensitive detection of thiram residues in tap water samples at the trace level. The thiram sensing mechanism of colorimetric probe was discussed in detail.

\section{Experimental Procedures}

2.1. Chemicals. Copper (II) chloride, sodium borohydride $\left(\mathrm{NaBH}_{4}\right)$, and Tween 80 were obtained from Shanghai Chemical Reagent. Thiram was obtained from Aladdin Reagent.

2.2. Preparation of Tween 80-Capped Copper Nanoparticles (Tween 80-CuNPs). Tween 80-capped copper nanoparticles (Tween 80 -CuNPs) were synthesized by the wet chemical reduction method following the reported procedure [23] with some modifications. In a typical approach to synthesize the Tween 80 -CuNPs, $0.35 \mathrm{~g}$ copper (II) chloride $(2.6 \mathrm{mmol})$ and $1.5 \mathrm{~mL}$ Tween 80 were mixed in $30 \mathrm{~mL}$ distilled water in a $100 \mathrm{~mL}$ round-bottom flask. The flask was degassed about 5-10 min before reaction was performed under an inert atmosphere with argon. After that, $0.2 \mathrm{~g}$ sodium borohydride $(5.28 \mathrm{mmol})$ dissolved in $5 \mathrm{~mL}$ distilled water was injected drop-by-drop into the mixture at a flow rate of $0.1 \mathrm{~mL} / \mathrm{min}$. After 50 minutes of total addition time, the color of the solution changed from blue-green to dark brown, indicating the formation of CuNPs.

2.3. Characterization Techniques. The UV-vis absorbance spectra were recorded from a UV-visible spectrometer (DR6000 spectrophotometer) between a wavelength of 400 and $800 \mathrm{~nm}$ using $10 \mathrm{~mm}$ quartz cuvettes for the measurement of the spectra. The crystalline structure of as-synthesized CuNPs was analyzed by X-ray diffraction spectra (XRD, Equinox 5000) using $\mathrm{Cu} \mathrm{K} \alpha$ radiation $(\lambda=0.154056 \mathrm{~nm})$. Transmission electron microscopy (TEM) observations were performed on a JEOL JEM 1010 transmission electron microscope (TEM) at an accelerating voltage of $80 \mathrm{kV}$. The FT-IR spectra were recorded on Agilent Cary 600 Series spectrometer to verify the interaction of CuNPs-Tween 80 with thiram.

2.4. Procedure for Colorimetric Detection of Thiram Pesticide. The colorimetric detection of thiram pesticide was performed at room temperature. According to the procedure, $10 \mathrm{~mL}$ of an analyte solution (Thiram) with different concentrations ranging from 0.5 to $25 \mu \mathrm{M}$ was added to $0.5 \mathrm{~mL}$ Tween 80 -CuNP solution. The change in color from dark brown to colorless was capture with a digital camera after mixing the solution for 15 minutes. The change in the SPR maximum of the Tween $80-\mathrm{CuNPs}$ was confirmed by $\mathrm{UV}$-vis spectrophotometer. The limit of detection (LOD) and limit of quantitation (LOQ) were calculated as LOD = $3 \mathrm{~S}_{\mathrm{b}} / \mathrm{b}$ and LOQ $=10 \mathrm{~S}_{\mathrm{b}} / \mathrm{b}$, respectively, where $S_{b}$ is the standard deviation of the blank solution, and $b$ is the slope of the analytical curve.

\section{Results and Discussion}

3.1. Characterization of Tween 80-Capped Copper Nanoparticles. $\mathrm{UV}$-vis, XRD, and TEM measurements were performed to investigate the crystalline structure, morphology, and size distribution of metallic CuNPs in aqueous solution. Figure 1(a) shows the UV-vis absorption spectrum of Tween 80-capped CuNPs. The result shows the absorption spectral peak at $575 \mathrm{~nm}$, which is the typical peak of metal CuNPs due to the surface plasmon resonance (SPR). This prove the formation 


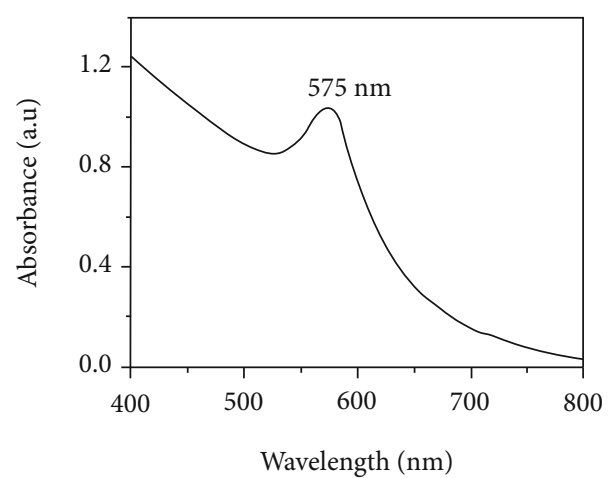

(a)

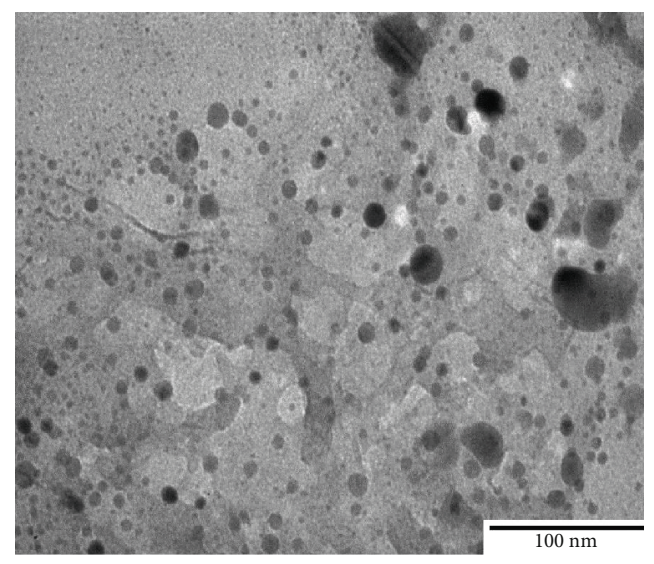

(c)

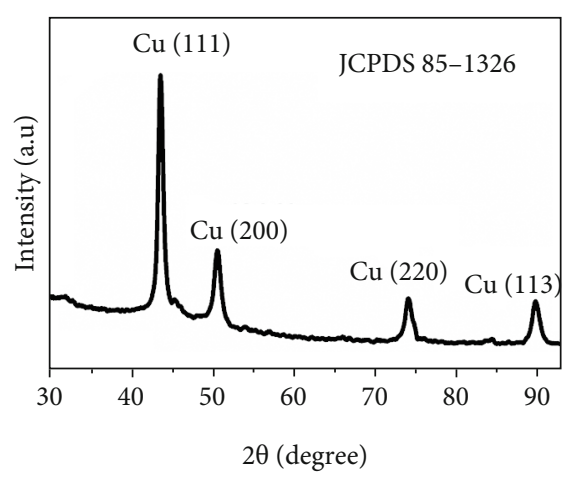

(b)

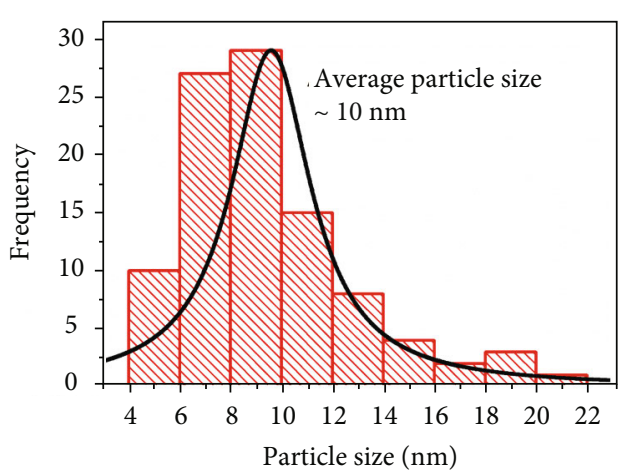

(d)

Figure 1: UV-vis (a), XRD patterns (b), TEM (c), and histogram of the particle size distribution (d) of Tween 80-capped copper nanoparticles.

of metallic copper nanoparticles in the solution. The XRD pattern of the as-synthesized CuNPs was shown in Figure 1(b). The results show four diffraction pattern peaks observed at $43.54^{\circ}, 50.54^{\circ}, 74.07^{\circ}$, and $89.74^{\circ}$, corresponding to (111), (200), (200), and (113) planes of face-centred-cubic (fcc) copper, respectively, and matching with the JCPDS no. 85-1326. There was no impurity phase of $\mathrm{CuO}, \mathrm{Cu}_{2} \mathrm{O}$, or $\mathrm{Cu}(\mathrm{OH})_{2}$, revealing the high purity of Tween 80 -capped CuNPs. These results indicated that the metallic copper nanoparticles were synthesized successfully. The morphology and size of the CuNPs were observed using a transmission electron microscopy (TEM). It is evident from Figure 1(c) that the formed copper particles were spherical and uniformly distributed in Tween 80 layer with an average particle size of $10 \mathrm{~nm}$ ranging from 4-22 $\mathrm{nm}$ (Figure 1(d)).

\subsection{Optimization of Conditions for Colorimetric Detection of} Thiram. The critical factor for colorimetric sensing of any analyte is the $\mathrm{pH}$ of the solution. To evaluate the effect of $\mathrm{pH}$ value on the interaction of Tween 80 -CuNPs with thiram pesticide, the UV-vis absorption spectra of Tween 80CuNPs in the absence and the presence of thiram with a $\mathrm{pH}$ range from 3 to 10 were recorded. At $\mathrm{pH}<6$, the color change from dark brown to yellow is accompanied by a noticeable shift in absorbance resulting from the CuNPs oxidation (Figure S1). In contrast, increasing basicity over $\mathrm{pH} 9$ of the solution leads to the self-aggregation of CuNPs with a concomitant red-shift in the SPR peak position. Figure S1(b) shows the change in absorbance $(\Delta A)$ of CuNPs in the presence of $10 \mu \mathrm{M}$ thiram with a $\mathrm{pH}$ range from 3 to 10 , and it can be concluded that $\mathrm{pH} 6.5$ provides the best performance of the CuNPs-based colorimetric sensor.

The concentration of NPs is a parameter for the effective detection of the analyte in colorimetric sensor. Therefore, different concentrations of Tween 80-capped CuNPs such as 29, $38.5,48,57.5,67$, and $76.5 \mathrm{ppm}$ were added to the thiram solution $(10 \mu \mathrm{M})$ with $\mathrm{pH} 6.5$ for the optimum detection of thiram. The absorbance ratio $\left(\mathrm{A}_{0} / \mathrm{A}\right)$ of the solution mixture in the presence of thiram increased with increasing the concentration of CuNPs from 38.5 to $57.5 \mathrm{ppm}$, and further addition did not increase the absorbance ratio (Figure S2(a)). Thus, $57.5 \mathrm{ppm}$ of CuNPs was selected as the optimized concentration for the colorimetric sensing of thiram pesticide. Figure S2(b) shows the optimization of the reaction time in the range of $1-15 \mathrm{~min}$ with $10 \mu \mathrm{M}$ thiram in $57.5 \mathrm{ppm}$ of CuNP solutions at $\mathrm{pH} 6.5$. The absorbance of $\mathrm{A}_{0} / \mathrm{A}$ was used as a measure of analytical response and suggest the best absorbance ratio after $5 \mathrm{~min}$ and was chosen as the optimum reaction time. Thus, we 


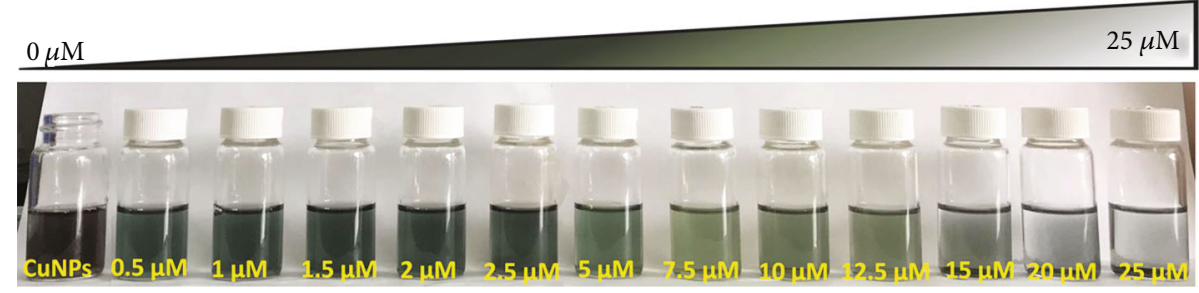

(a)

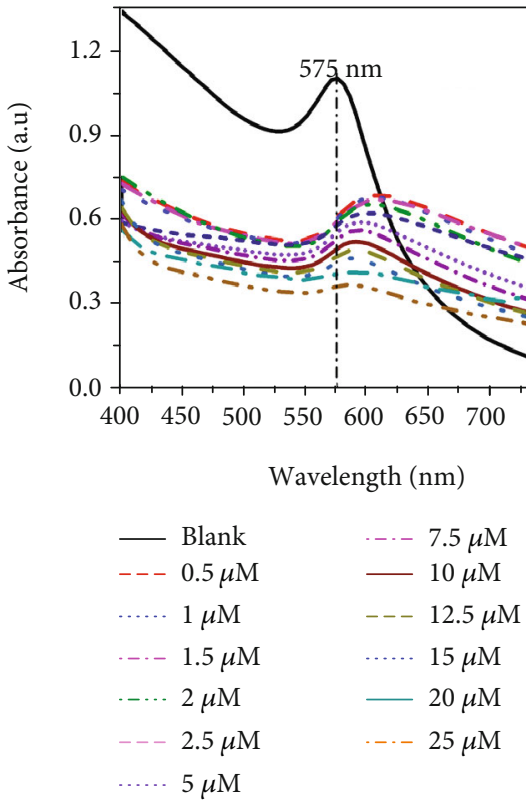

(b)

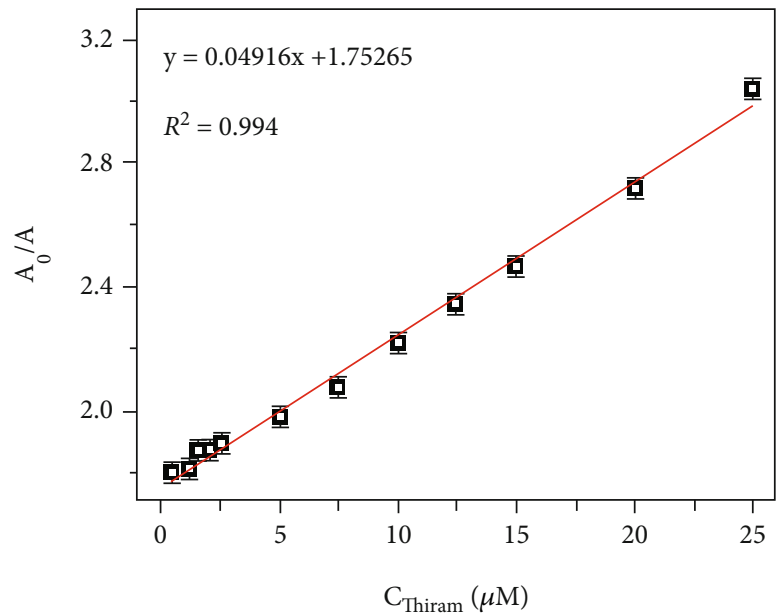

(c)

Figure 2: Photograph (a) and UV-vis absorbance spectra (b) of Tween 80-CuNPs in the presence of a defined concentration of thiram pesticide $(0-25 \mu \mathrm{M})$; (c) the plot of absorbance ratio $\left(\mathrm{A}_{0} / \mathrm{A}\right)$ against the concentration of thiram in the range of $0-25 \mu \mathrm{M}$ and its linear calibration curve ( $A_{0}$ and $A$ are the absorbances of Tween 80 -CuNPs at $575 \mathrm{~nm}$ without or with thiram, respectively).

selected the experimental conditions such as optimal $\mathrm{pH}$ of 6.5 , the best Tween 80-capped CuNP concentration of $57.5 \mathrm{ppm}$, and the suitable reaction time of $5 \mathrm{~min}$ for the subsequent experiments.

\subsection{The Sensitivity of the Colorimetric Sensor for Thiram.} Under the optimum condition, the colorimetric response of Tween 80-CuNPs towards different concentrations of thiram was examined by UV-vis spectra and the color change of solutions. The photograph of Tween 80 -CuNPs in the presence of different thiram concentrations (Figure 2(a)) showed obvious differences in color from dark brown to olive green and finally to colorless with the increasing thiram concentration. For the quantitative detection of thiram, the UV-vis spectrophotometer for the absorption spectra of Tween 80-CuNPs after addition thiram was recorded. As shown in Figure 2(b), it is clear that there was a decrease in the absorption intensity and redshift in the characteristic SPR band of CuNPs. Figure 2(c) shows the plot of $\mathrm{A}_{0} / \mathrm{A}$ against the concentration of thiram ( $A_{0}$ and $A$ are the absorbances of CuNPs at $575 \mathrm{~nm}$ without or with thiram, respectively). The calibration curve exhibited a good linear relationship in the calibration range $0.5-25 \mu \mathrm{M}$ of thiram concentrations. The correlation coefficient $\left(R^{2}\right)$ was 0.994 , with the limit of detection (LOD) of $0.17 \mu \mathrm{M}$ and the limit of quantification (LOQ) of $0.57 \mu \mathrm{M}$.

3.4. Selectivity and Interference Study. Next, we evaluated Tween 80-CuNPs-based colorimetric sensor's specificity towards thiram detection compared to other pesticides such as chlorpyrifos, fipronil, tricyclazone, carbaryl at concentrations 5 times higher than that of thiram. As shown in Figures 3(a) and 3(b), only thiram imparts noticeable color change on the Tween 80-capped CuNPs solutions along with a decrease and red-shift in absorption spectra. In contrast, there was a negligible change in color and absorbance after the addition of other pesticides.

To further evaluate the potential application of Tween 80-capped CuNP-based colorimetric sensor for the determination of thiram pesticide in real water samples, the interference study of metal ions and anions in the detection thiram 


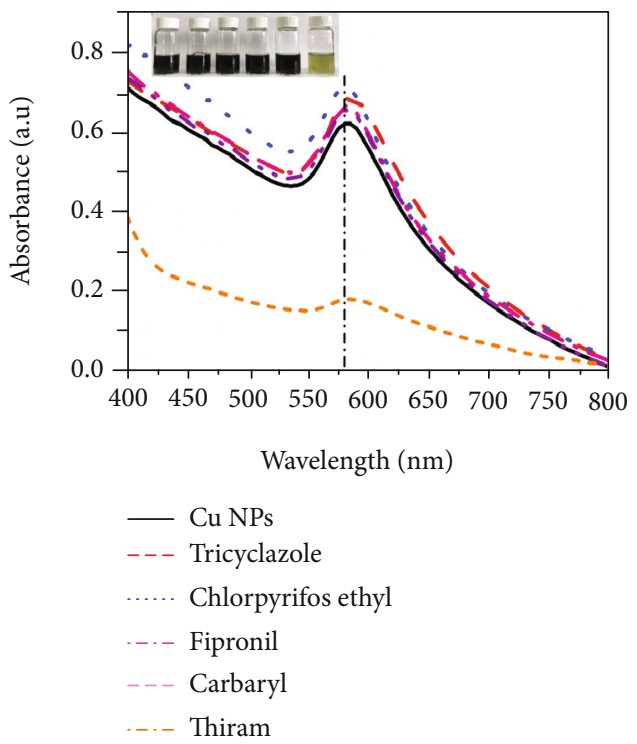

(a)
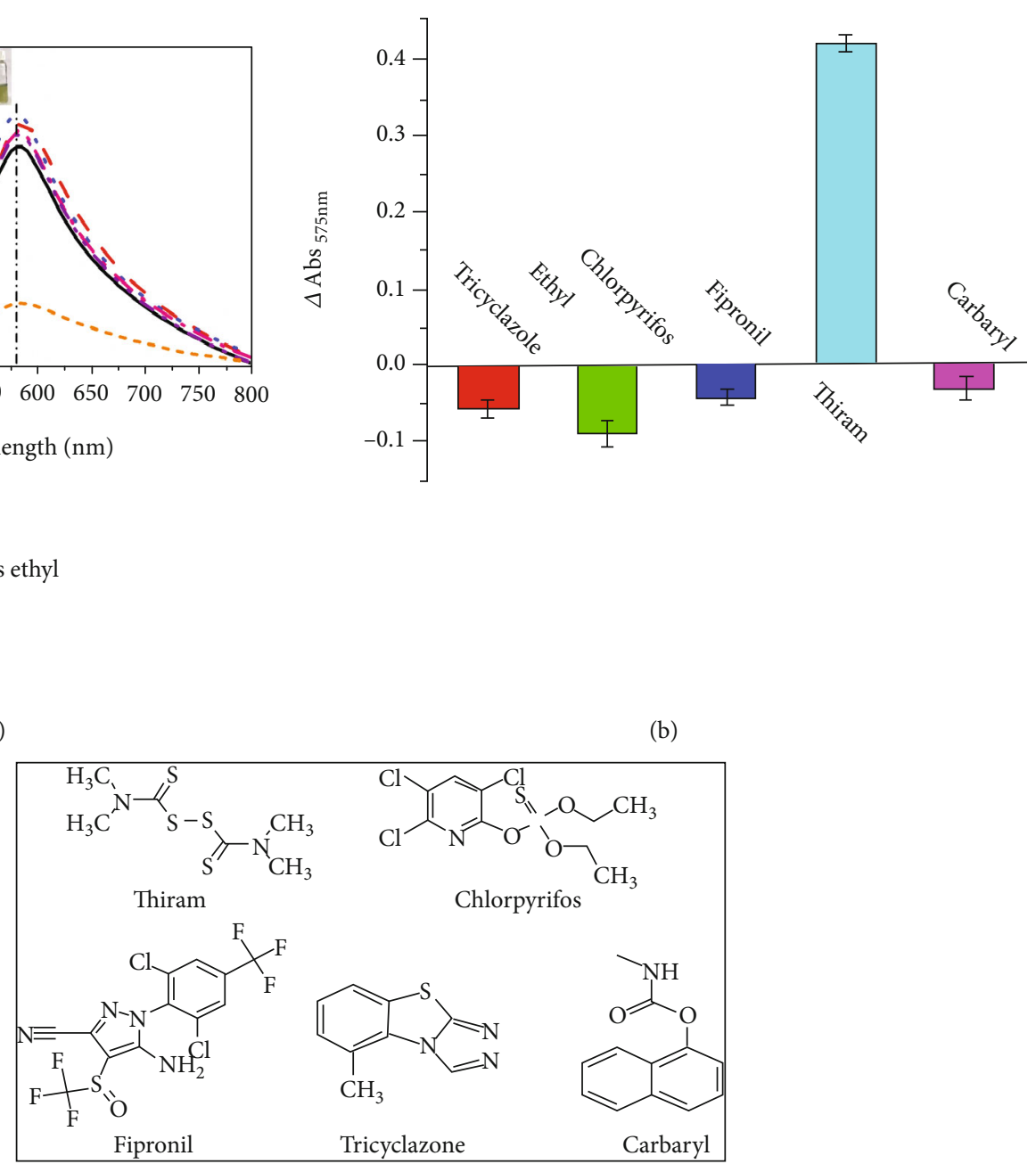

(c)

Figure 3: (a) UV-vis spectra of Tween 80-functionalized CuNPs in the presence of thiram or other pesticides (the concentrations of thiram were $10 \mu \mathrm{M}$ and other pesticides were $50 \mu \mathrm{M}$ ); insert a photographic image of selectivity; (b) the bar graphs exhibiting magnitude of change $\Delta A$ ( $\triangle A$ was the change in absorbance at $575 \mathrm{~nm}$ of CuNPs in the presence of different pesticides); (c) the chemical structures of all the pesticides used for the selectivity study.

was subjected. $15 \mu \mathrm{M}$ of thiram and the mixtures containing $10 \mu \mathrm{M}$ of thiram and $50 \mu \mathrm{M}$ of different cations $\left(\mathrm{Mn}^{2+}, \mathrm{Cr}^{6+}\right.$, $\mathrm{Co}^{2+}$, and $\left.\mathrm{Ni}^{2+}\right)$ and anion $\left(\mathrm{Cl}^{-}, \mathrm{NO}_{3}{ }^{-}\right.$, and $\left.\mathrm{C}_{2} \mathrm{O}_{7}{ }^{2-}\right)$ were added into the Tween $80-\mathrm{CuNPs}$ aqueous solution. From the results shown in Figure 4, in comparison with the absorption changes of thiram, the influence from the coexisting background metal ions as well as anions is negligible. These results demonstrate that the ions and other pesticides have no interference to thiram detection and supports that the Tween 80-capped CuNPs-based colorimetric probe can detect thiram in the presence of other natural interfering substances.

3.5. Mechanism of Thiram Detection. Tween 80, a nonionic surfactant, is commonly used to stabilize noble metal nanoparticles. Tween 80 with the hydrophilic polar head has been considered as a sorbitan ring, in which the 4 hydroxyl $(\mathrm{OH})$ groups are replaced by polyoxyethylene $\left(\mathrm{CH}_{2} \mathrm{CH}_{2} \mathrm{O}\right)$ polymer groups. The fourth polyoxyethylene polymer replaced the secondary hydroxyl group associated with an oleic acid moiety to form the hydrophobic nonpolar tail of the structure [24]. Tween 80 interacts with CuNPs through surface adsorption mechanism [25]. Several previous studies indicated the formation as well as the stability of CuNPs due to the strong coordinative interaction between the oxygen atom of polyoxyethylene chains and CuNPs [26-29]. The Tween 80-CuNPs are separated by the steric repulsion mechanism $[25,27]$. In the presence of thiram, Tween 80 -CuNPs were aggregated, which induced a color change of the solution from dark brown to olive green as well as SPR band in the UV-vis spectra. TEM observations were used to confirm the stabilization of the Tween 80 CuNPs and their aggregation process in the presence of thiram (see Figure 5). It can be seen that the CuNPs were aggregated in the presence of thiram (Figure 5(b)). The aggregation of Tween 80-CuNPs by thiram can be due to the interaction of Tween 80 $\mathrm{CuNPs}$ with thiram via the formation of $\mathrm{Cu}-\mathrm{S}$ bonds. 


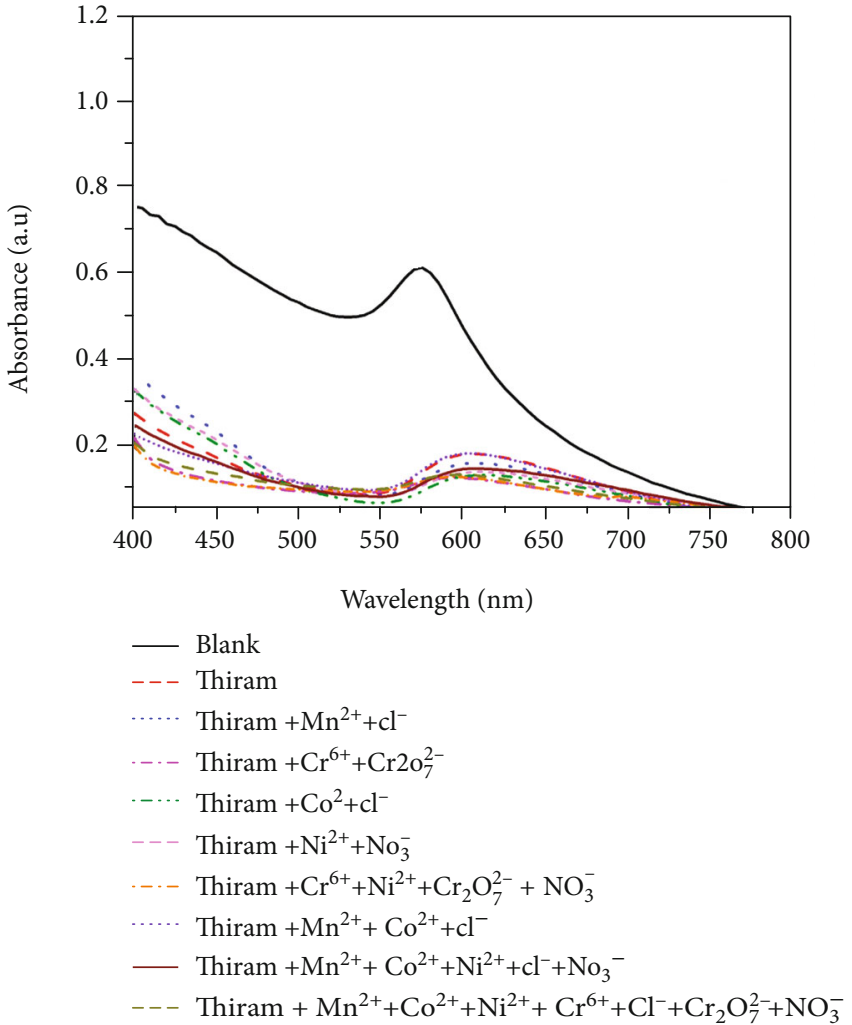

(a)

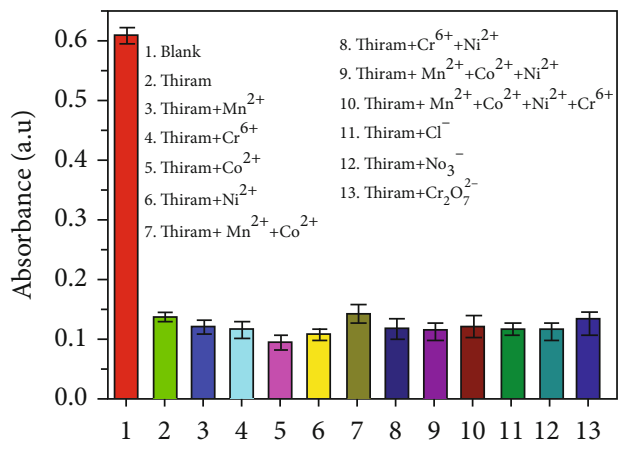

(b)

Figure 4: Interference of different cations and anions on the determination of thiram using Tween 80-capped CuNPs as a plasmon colorimetric sensor.

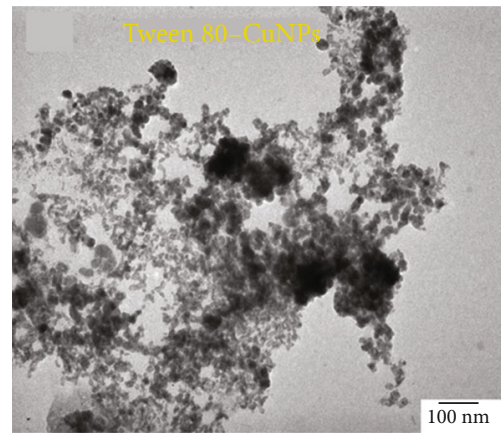

(a)

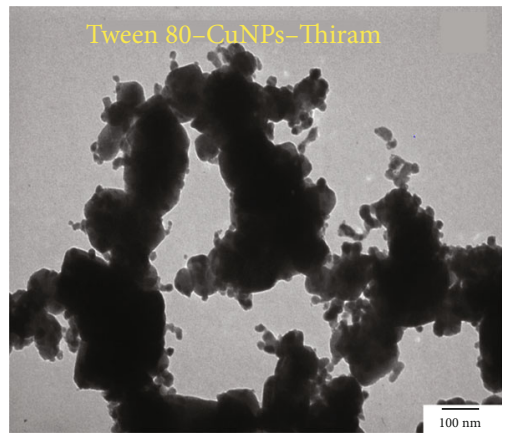

(b)

FIgURE 5: TEM images of CuNPs in the absence (a) and presence (b) of thiram.

To further clarify the interaction of Tween 80 -CuNPs with thiram, Fourier-transform infrared (FTIR) spectroscopy measurement was carried out. Figure 6 shows the FTIR spectra of thiram and CuNPs-thiram, respectively. Thiram is the simplest thiuram disulfide and the oxidized dimer of diethyldithiocarbamate. The spectra of dithiocarbamate are often characterized by three crucial absorption regions, primarily associated with the stretching vibrational bands of $v(\mathrm{C}-\mathrm{N}), v(\mathrm{C}-\mathrm{S})$, and $v(\mathrm{M}-\mathrm{S})[30,31]$. Both thiram and CuNPs-thiram showed the absorption band at about 1450-
$1550 \mathrm{~cm}^{-1}$ characteristic for C-N bond stretching [30, 31]. For dithiocarbamate ligands, it was shown that there are often two types of $v(\mathrm{C}-\mathrm{S})$ band. The presence of adsorption bands appear around $1055 \mathrm{~cm}^{-1}$, and $961 \mathrm{~cm}^{-1}$ corresponds to asymmetric and symmetric stretching vibrational of $\mathrm{CS}_{2}$, respectively [31]. For the case of CuNPs-thiram, the appearance of a new band was observed at $1000 \mathrm{~cm}^{-1}$, which implies symmetrical coordination of two sulfur atoms of dimethyldithocarbamate fragment due to the thiram molecule undergo cleavage of S-S bond when interacting with CuNPs 


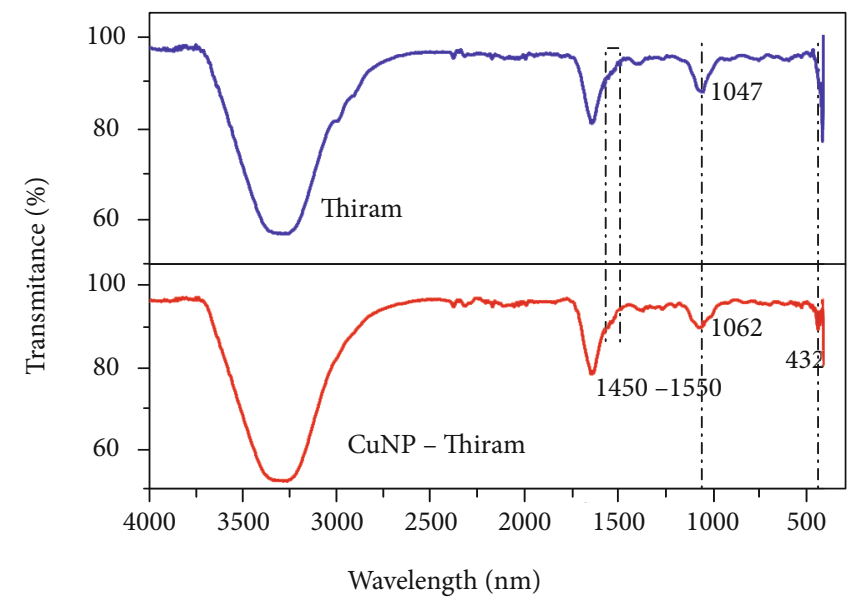

FIgURe 6: FTIR spectra of thiram (blue line) and CuNPs-thiram (red line).
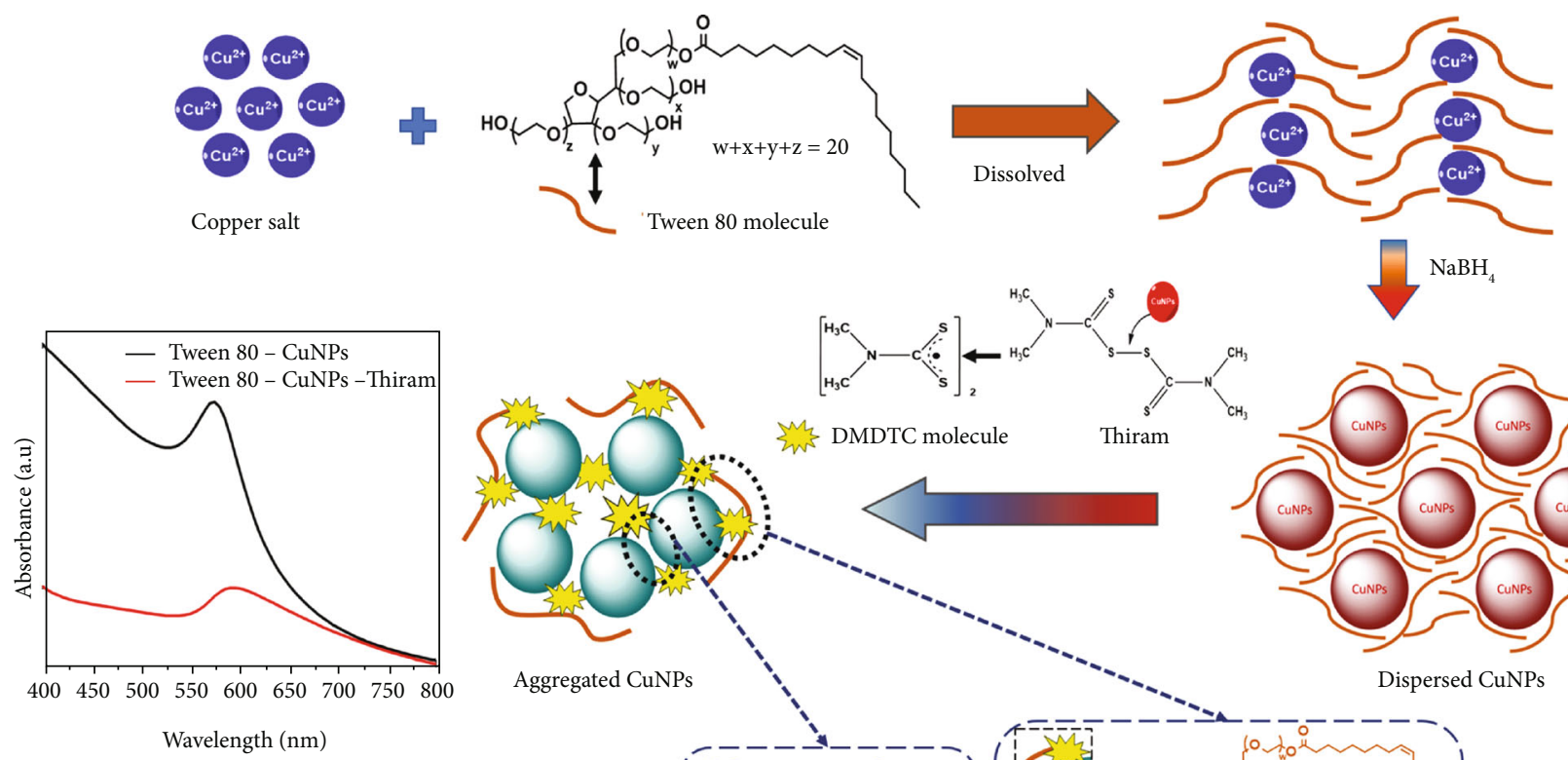

Copper salt
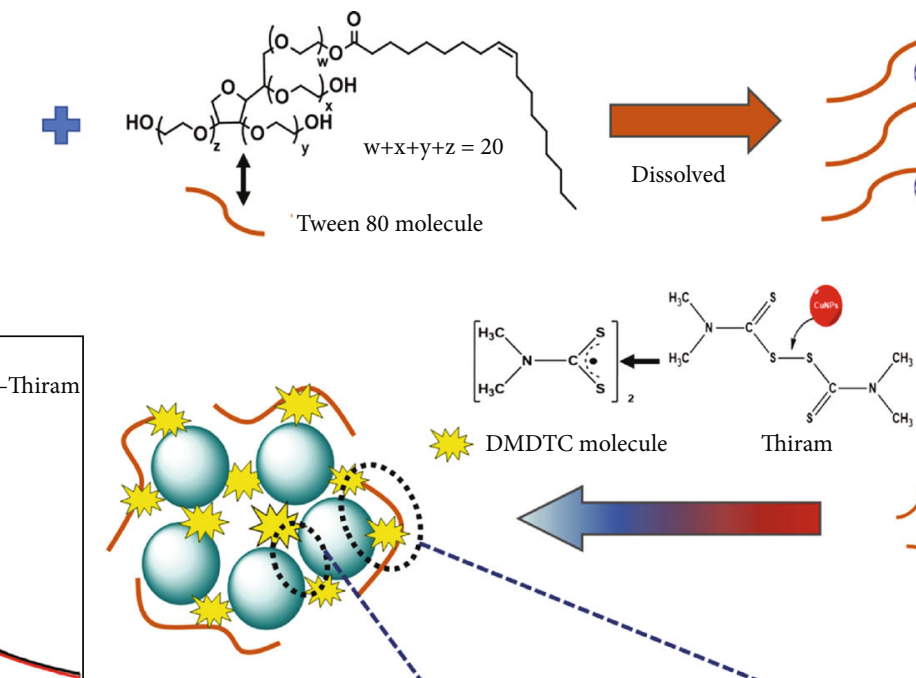

$\prod \mathrm{NaBH}_{4}$

Wavelength (nm)

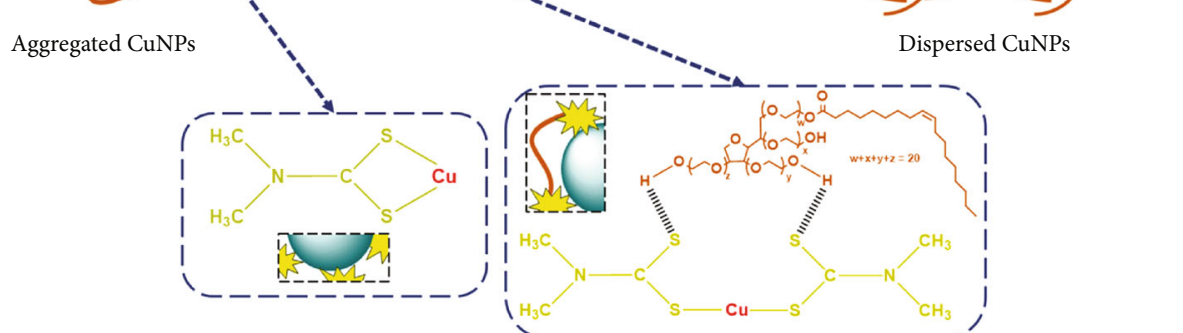

FIgURE 7: Schematic illustration for the colorimetric detection of thiram using CuNP-Tween 80 as a colorimetric assay.

$[6,30-33]$. The shift of the stretching vibrational band of $v(\mathrm{C}-\mathrm{S})$ asym to a high frequency of about $15 \mathrm{~cm}^{-1}$ upon interaction with CuNPs often suggests that the delocalisation of electron will affect the C-S bond [31]. A new sharp band at $432 \mathrm{~cm}^{-1}$ observed in the FTIR spectrum of CuNPs-thiram can be attributed to the $v(\mathrm{Cu}-\mathrm{S})$ stretching vibration band [30,34].

Based on obtained results, a mechanism for selective sensing thiram pesticide using Tween 80 -CuNPs is proposed (Figure 7). The sensing mechanism is based on the strong chemisorptions between thiram molecule on copper nanoparticles surface due to high affinity of copper metal with
TABLE 1: Analysis of thiram from tap water samples using Tween 80 -capped CuNPs as a colorimetric sensor. $(n=3)$.

\begin{tabular}{lccc}
\hline Added $(\mu \mathrm{M})$ & Found $(\mu \mathrm{M})$ & Recovery $(\%)$ & RSD $(\%)^{\mathrm{n}}$ \\
\hline 5 & 4.9 & 98 & 1.6 \\
15 & 15.2 & 101 & 2.8 \\
25 & 27.9 & 107 & 2.7 \\
\hline
\end{tabular}

sulfur-containing groups $[6,35]$ and the interaction of thiram with Tween 80 . Once interacting with CuNPs, the thiram molecule undergoes cleavage of S-S bond in structure 
TABLE 2: Comparison of the proposed method with some of the methods reported in the literature for the determination of thiram.

\begin{tabular}{|c|c|c|c|}
\hline Name of the techniques & Linear range $(\mathrm{M})$ & LOD (M) & References \\
\hline LC-MS & $8.3 \times 10^{-8}-4.1 \times 10^{-6}$ & $2.49 \times 10^{-9}$ & [37] \\
\hline HPLC & $4.2 \times 10^{-6}-4.2 \times 10^{-5}$ & $5.28 \times 10^{-7}$ & [38] \\
\hline Voltammetry & $1 \times 10^{-6}-6 \times 10^{-4}$ & $4.34 \times 10^{-7}$ & [39] \\
\hline Ag dendritic nanostructure-based surface enhanced Raman scattering (SERS) & $10^{-7}-10^{-4}$ & $1 \times 10^{-7}$ & {$[40]$} \\
\hline Ag nanowire-based surface enhanced Raman scattering (SERS) & $10^{-7}-5 \times 10^{-6}$ & $1 \times 10^{-7}$ & {$[41]$} \\
\hline CTAB-Au NP-based colorimetric assay & $2 \times 10^{-7}-1 \times 10^{-5}$ & $1.7 \times 10^{-7}$ & {$[22]$} \\
\hline CN-DTC-Ag NP-based colorimetric assay & $2.5 \times 10^{-6}-2 \times 10^{-5}$ & $2.81 \times 10^{-6}$ & {$[21]$} \\
\hline Tween 80-CuNP-based colorimetric assay & $0.5 \times 10^{-6}-2.5 \times 10^{-5}$ & $1.7 \times 10^{-7}$ & Present study \\
\hline
\end{tabular}

of thiram to two dimethylthiocarbamate (DMDTC) fragments that are strongly adsorbed onto the surface of CuNPs [6, 32, 36]. Two $\mathrm{S}$ atoms of two different DMDTC molecules can bond with CuNPs that form a bridge between these two molecules. The remaining sulfur atom of DMDTC can link with a hydrogen atom in the $-\mathrm{OH}$ group at the hydrophilic polar head of Tween 80 to form -SH bond, breaking welldispersed state of CuNPs created by Tween 80 . Therefore, the color change of Tween 80 -CuNPs solution from dark brown to olive green can be due to the aggregation of CuNPs by DMDTC residues. Moreover, for other pesticides, they contain aromatic rings and large size substituents and do not have $\mathrm{S}-\mathrm{S}$ bond leading to significant barriers to form new bonds due to steric effects. Thus, sterically hindered aromatic compounds with stable structures are difficult to link to the surface of CuNPs.

3.6. Colorimetric Detection of Thiram in Tap Water Samples and Its Repeatability. The practical application of our developed sensor based on Tween 80-CuNPs was evaluated for the determination of thiram in environmental water samples (tap water) by recovery experiments. The ultimate concentration of thiram present in the water sample was determined using the standard calibration curve in Figure 2(c). The obtained results are shown in Table 1 . The recoveries were between 98 and 107\% with the relative standard deviations (RSD) within 2.8, demonstrating the proposed sensor can hold practical potentiality in facile thiram detection in environmental water samples.

The repeatability experiments for the colorimetric detection of thiram in distilled water and tap water samples were carried out and shown in Figure S3. The absorbance of Tween 80-CuNPs solutions before and after adding thiram solutions $(25 \mu \mathrm{M})$ in distilled water and tap water was chosen as parameters to characterize the colorimetric sensor's repeatability. The relative standard deviation (RSD) values of the Tween $80-\mathrm{CuNPs}$ and Tween $80-\mathrm{CuNPs}$ containing Thiram in distilled water and tap water are $1 \%$, $3.2 \%$, and $1.9 \%$, respectively. Therefore, the obtained Tween 80-capped CuNPs are reliable and repeatable platforms for the colorimetric detection of thiram in environmental water samples.
The present method has been compared with other analytical techniques as well as other NPs-based colorimetric methods 424 the Tween 80-CuNPs-based colorimetric sensor enabled sufficiently sensitive for the determination of thiram in water with a limit of detection (LOD) of $0.17 \mu \mathrm{M}$ $(0.041 \mathrm{mg} / \mathrm{kg})$ which is lower than the maximum residue limit (MRL) regulated by the governments of EU and Vietnam $(0.1-10 \mathrm{mg} / \mathrm{kg})$. Furthermore, another aspect of the cost of gold and silver nanoparticles, the use of Tween 80-capped CuNPs in colorimetric sensors would be cost-effective for the routine determination. More importantly, Table 2 further reveals that the use of Tween 80 -CuNPs for colorimetric sensor for detection thiram is the first study of its kind. With such obtained results, we believe that this method is very simple, rapid, highly sensitive, and low-cost and has a high potential for environmental monitoring of thiram pesticide.

\section{Conclusions}

In summary, the Tween 80 -CuNPs have been tested as colorimetric probe for the detection of thiram pesticide in aqueous solution. The sensing mechanism of this colorimetric probe can be explained based on the interaction of thiram with Tween 80 and the cleavage of S-S bond in the structure of thiram when interacting with the surface of CuNPs. This sensor furnished a rapid response time within 5 minutes with a limit of detection (LOD) of $0.17 \mu \mathrm{M}(0.041 \mathrm{mg} / \mathrm{kg})$ which is below the maximum residue limits that were set by the European Union and Vietnam $(0.1-10 \mathrm{mg} / \mathrm{kg})$. The method was tested for the determination of thiram in tap water samples with a percentage recovery of $98-107 \%$ and $\mathrm{RSD}=1.9 \%$. To the best of our knowledge, this is the first study concerning the employment of Tween 80-capped CuNPs as a colorimetric sensor for the detection of thiram pesticide in environmental water samples. Considering the high costs of noble metals such as AuNPs and AgNPs, the proposed sensor based on Tween 80-capped CuNPs would be a cost-effective sensing platform for environmental monitoring to determine multiple pesticide residues routinely.

\section{Data Availability}

Data are available on request. 


\section{Conflicts of Interest}

The authors declare that they have no conflicts of interest.

\section{Authors' Contributions}

Nguyen Tuan Anh and Ngo Xuan Dinh contributed equally to this work.

\section{Acknowledgments}

This research was supported by the Vietnam National Foundation for Science and Technology Development (NAFOSTED) through a fundamental research project (103.02-2018.48). The authors would like to acknowledge the supports with FTIR and UV-Vis measurements from NEB Lab at the Phenikaa University.

\section{Supplementary Materials}

Figure S1: (a) photographs of glass vials containing solution mixtures of CuNPs before and after the addition of thiram; dependence of the surface plasmon intensity on stability of Tween 80-modified CuNPs in the absence and presence thiram pesticide (b) and the change in absorbance intensity (c) with $\mathrm{pH}$ range from 3 to 10 . Figure S2: dependence of absorbance ratio $\left(A_{0} / A\right)$ on the concentrations of Tween 80 modified CuNPs (a) and reaction time (b) in the presence of thiram $(10 \mu \mathrm{M})$ at $\mathrm{pH} 6.5$. $\left(A_{0}\right.$ and $A$ are the absorbances of Tween 80 -CuNPs in the absence or presence thiram, respectively). Figure S3: reliable and repeatable colorimetric detection of thiram using Tween 80-modified CuNPs. Black bar represents the absorption intensity of CuNPs, red bar represents the absorption intensity of CuNPs + thiram in distilled water, and blue bar represents the absorption intensity of CuNPs + thiram in tap water recorded from UV-vis spectra of 10 same samples. The concentration of thiram is $25 \mu \mathrm{M}$. (Supplementary Materials)

\section{References}

[1] D. J. Ecobichon, "Pesticide use in developing countries," Toxicology, vol. 160, no. 1-3, pp. 27-33, 2001.

[2] F. P. Carvalho, "Pesticides, environment, and food safety," Food and Energy Security, vol. 6, no. 2, pp. 48-60, 2017.

[3] P. J. Nieuwenhuizen, A. W. Ehlers, J. G. Haasnoot, S. R. Janse, J. Reedijk, and E. J. Baerends, "The mechanism of zinc(II)dithiocarbamate-accelerated vulcanization uncovered; theoretical and experimental evidence," Journal of the American Chemical Society, vol. 121, no. 1, pp. 163-168, 1999.

[4] C. Rafin, E. Veignie, M. Sancholle et al., "Synthesis and antifungal activity of novel bisdithiocarbamate derivatives of carbohydrates against Fusarium oxysporum f. sp. lini," Journal of Agricultural and Food Chemistry, vol. 48, no. 11, pp. 5283-5287, 2000.

[5] A. J. Odola and J. A. O. Woods, "New nickel(II) mixed ligand complexes of dithiocarbamates with schiff base," Journal of Chemical and Pharmaceutical Research, vol. 3, no. 6, pp. 865-871, 2011.
[6] S. Chu, H. Wang, X. Ling, S. Yu, L. Yang, and C. Jiang, “A portable smartphone platform using a ratiometric fluorescent paper strip for visual quantitative sensing," ACS Applied Materials \& Interfaces, vol. 12, no. 11, pp. 12962-12971, 2020.

[7] M. Chen, W. Luo, Q. Liu et al., "Simultaneous in situ extraction and fabrication of surface-enhanced Raman scattering substrate for reliable detection of thiram residue," Analytical Chemistry, vol. 90, no. 22, pp. 13647-13654, 2018.

[8] B. Wang, L. Zhang, and X. Zhou, "Synthesis of silver nanocubes as a SERS substrate for the determination of pesticide paraoxon and thiram," Spectrochimica Acta Part A: Molecular and Biomolecular Spectroscopy, vol. 121, pp. 63-69, 2014.

[9] European Union, "EU pesticide database," https://ec.europa .eu/food/plant/pesticides/eu-pesticides-database/mrls/?event= details\&pest_res_ids=214\&product_ids=\&v=1\&e=search.pr.

[10] O. M. S. Filipe, M. M. Vidal, A. C. Duarte, and E. B. H. Santos, "A solid-phase extraction procedure for the clean-up of thiram from aqueous solutions containing high concentrations of humic substances," Talanta, vol. 72, no. 3, pp. 1235-1238, 2007.

[11] S. Rastegarzadeh, N. Pourreza, and A. Larki, "Dispersive liquid-liquid microextraction of thiram followed by microvolume UV-vis spectrophotometric determination," Spectrochimica Acta Part A: Molecular and Biomolecular Spectroscopy, vol. 114, pp. 46-50, 2013.

[12] B. Gupta, M. Rani, R. Kumar, and P. Dureja, "Identification of degradation products of thiram in water, soil and plants using LC-MS technique," Journal of Environmental Science and Health, Part B, vol. 47, no. 8, pp. 823-831, 2012.

[13] A. Peruga, S. Grimalt, F. J. López, J. V. Sancho, and F. Hernández, "Optimisation and validation of a specific analytical method for the determination of thiram residues in fruits and vegetables by LC-MS/MS," Food Chemistry, vol. 135, no. 1, pp. 186-192, 2012.

[14] P. Maini and R. Boni, "Gas chromatographic determination of dithiocarbamate fungicides in workroom air," Bulletin of Environmental Contamination and Toxicology, vol. 37, no. 1, pp. 931-937, 1986.

[15] A.-L. Queffelec, F. Boisdé, J.-P. Larue et al., "Development of an immunoassay (ELISA) for the quantification of thiram in lettuce," Journal of Agricultural and Food Chemistry, vol. 49, no. 4, pp. 1675-1680, 2001.

[16] S. B. Ekroth, B. Ohlin, and B. G. Österdahl, "Rapid and simple method for determination of thiram in fruits and vegetables with high-performance liquid chromatography with ultraviolet detection," Journal of Agricultural and Food Chemistry, vol. 46, no. 12, pp. 5302-5304, 1998.

[17] Z. Zhang, H. Wang, Z. Chen, X. Wang, J. Choo, and L. Chen, "Plasmonic colorimetric sensors based on etching and growth of noble metal nanoparticles: strategies and applications," Biosensors \& Bioelectronics, vol. 114, pp. 52-65, 2018.

[18] P. Prosposito, L. Burratti, and I. Venditti, "Silver nanoparticles as colorimetric sensors for water pollutants," Chemosensors, vol. 8, no. 2, 2020.

[19] R. Singh, P. Thakur, A. Thakur et al., "Colorimetric sensing approaches of surface-modified gold and silver nanoparticles for detection of residual pesticides: a review," International Journal of Environmental Analytical Chemistry, pp. 1-17, 2020.

[20] D. Vilela, M. C. González, and A. Escarpa, "Sensing colorimetric approaches based on gold and silver nanoparticles 
aggregation: chemical creativity behind the assay. A review," Analytica Chimica Acta, vol. 751, pp. 24-43, 2012.

[21] J. V. Rohit and S. K. Kailasa, "Cyclen dithiocarbamatefunctionalized silver nanoparticles as a probe for colorimetric sensing of thiram and paraquat pesticides via host-guest chemistry," Journal of Nanoparticle Research, vol. 16, no. 11, 2014.

[22] S. Rastegarzadeh and S. Abdali, "Colorimetric determination of thiram based on formation of gold nanoparticles using ascorbic acid," Talanta, vol. 104, pp. 22-26, 2013.

[23] T. Abeywickrama, N. N. Sreeramulu, L. Xu, and H. Rathnayake, "A versatile method to prepare size- and shape-controlled copper nanocubes using an aqueous phase green synthesis," RSC Advances, vol. 6, no. 94, pp. 9194991955, 2016.

[24] D. Joseph, H. Lee, Y. S. Huh, and Y. K. Han, "Cylindrical coreshell tween 80 micelle templated green synthesis of gold-silver hollow cubic nanostructures as efficient nanocatalysts," Materials and Design, vol. 160, pp. 169-178, 2018.

[25] V.-T. Hoang, M. Mai, L. T. Tam et al., "Functionalized-AgNPs for long-term stability and its applicability in the detection of manganese ions," Advances in Polymer Technology, vol. 2020, 9 pages, 2020.

[26] X. Zhang, H. Yin, X. Cheng, H. Hu, Q. Yu, and A. Wang, "Effects of various polyoxyethylene sorbitan monooils (tweens) and sodium dodecyl sulfate on reflux synthesis of copper nanoparticles," Materials Research Bulletin, vol. 41, no. 11, pp. 2041-2048, 2006.

[27] J. H. Lee, B. E. Park, Y. M. Lee, S. H. Hwang, and W. B. Ko, "Synthesis of fullerene[C60]-silver nanoparticles using various non-ionic surfactants under microwave irradiation," Current Applied Physics, vol. 9, no. 2, pp. e152-e156, 2009.

[28] H. J. Li, A. Q. Zhang, Y. Hu, L. Sui, D. J. Qian, and M. Chen, "Large-scale synthesis and self-organization of silver nanoparticles with Tween 80 as a reductant and stabilizer," Nanoscale Research Letters, vol. 7, no. 10, pp. 1-13, 2012.

[29] T. Premkumar, D. Kim, K. Lee, and K. E. Geckeler, "Polysorbate 80 as a tool: synthesis of gold nanoparticles," Macromolecular Rapid Communications, vol. 28, no. 7, pp. 888-893, 2007.

[30] J. O. Adeyemi and D. C. Onwudiwe, "Organotin(IV) dithiocarbamate complexes: chemistry and biological activity," Molecules, vol. 23, no. 10, pp. 1-27, 2018.

[31] A. Al Bawab, A. Bozeya, and F. Odeh, "Synthesis, characterization and biological activity of organitin (IV) complexes featuring di-2-ethyldithiocarbamate and N-methylbutyldithiocarbamate as ligands," GSTF Journal of Chemical Sciences (JChem), vol. 1, no. 2, pp. 32-39, 2015.

[32] B. Liu, G. Han, Z. Zhang et al., "Shell thickness-dependent Raman enhancement for rapid identification and detection of pesticide residues at fruit peels," Analytical Chemistry, vol. 84, no. 1, pp. 255-261, 2012.

[33] P. Morf, F. Raimondi, H.-G. Nothofer et al., "Dithiocarbamates: functional and versatile linkers for the formation of self-assembled monolayers," Langmuir, vol. 22, no. 2, pp. 658-663, 2006.

[34] K. K. Venugopal, "Synthesis and characterization of furfuryl amine dithiocarbamate ( Fadtc) ligand and it's metal complexes," World Journal of Pharmaceutical Sciences, vol. 4, no. 4, pp. 1116-1127, 2015.
[35] X. Liang, Y.-S. Wang, T.-T. You et al., "Interfacial synthesis of a three-dimensional hierarchical MoS 2 -NS@Ag-NP nanocomposite as a SERS nanosensor for ultrasensitive thiram detection," Nanoscale, vol. 9, no. 25, pp. 8879-8888, 2017.

[36] J. S. Kang, S. Y. Hwang, C. J. Lee, and M. S. Lee, "SERS of dithiocarbamate pesticides adsorbed on silver surface; thiram," Bulletin of the Korean Chemical Society, vol. 23, no. 11, pp. 1604-1610, 2002.

[37] D. Ringli and W. Schwack, "Selective determination of thiram residues in fruit and vegetables by hydrophilic interaction LCMS," Food Addit. Contam. Part A, vol. 30, no. 11, pp. 19091917, 2013.

[38] C. Fernhdez, A. J. Reviejo, L. M. Polo, and J. M. Pingarrbn, "HPLC-Electrochemical detection with graphite-poly (tetrafluoroethylene) electrode Determination of the fungicides thiram and disulfiram," Talanta, vol. 43, no. 8, pp. 1341-1348, 1996.

[39] K. Nováková, T. Navrátil, J. J. Dytrtová, and J. Chýlková, “The use of copper solid amalgam electrodes for determination of the pesticide thiram," Journal of Solid State Electrochemistry, vol. 17, no. 6, pp. 1517-1528, 2013.

[40] Q. Wang, D. Wu, and Z. Chen, “Ag dendritic nanostructures for rapid detection of thiram based on surface-enhanced Raman scattering," RSC Advances, vol. 5, no. 86, pp. 7055370557, 2015.

[41] L. Zhang, B. Wang, G. Zhu, and X. Zhou, "Synthesis of silver nanowires as a SERS substrate for the detection of pesticide thiram," Spectrochimica Acta Part A: Molecular and Biomolecular Spectroscopy, vol. 133, pp. 411-416, 2014. 